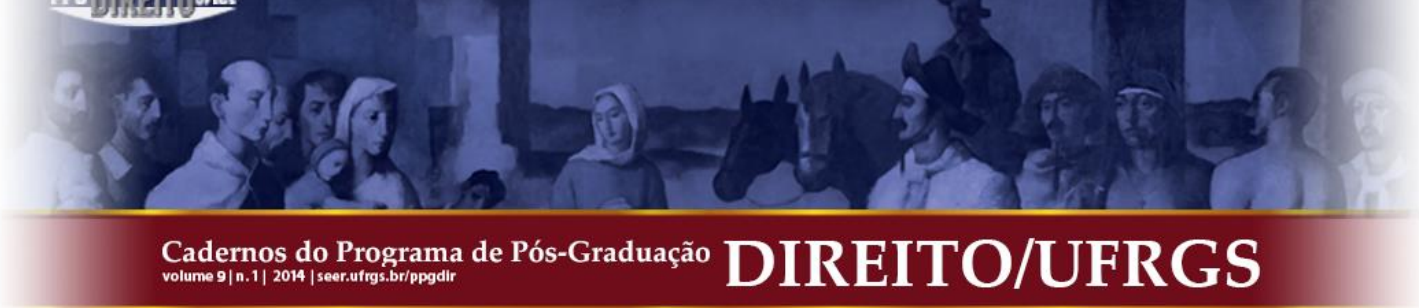

\title{
OS OBJETIVOS DO DIREITO DA CONCORRÊNCIA EM FACE DA ORDEM ECONÔMICA NACIONAL
}

\author{
THE OBJECTIVES OF COMPETITION LAW REGARDING NATIONAL ECONOMIC ORDER
}

\author{
Luiz Carlos Buchain*
}

\begin{abstract}
RESUMO: A Constituição Federal brasileira, ao adotar o princípio da livre iniciativa para a Ordem Econômica, também acatou a liberdade de empresa como fundamento destinado a estabelecer a ampla concorrência de mercado entre agentes econômicos. Entretanto, como demonstra a história econômica, a liberdade econômica traz em si a concentração de poder econômico nas mãos de determinadas empresas (ou grupo). Tal concentração de poder é considerada uma das falhas de mercado porque possibilita ao seu detentor adotar determinados comportamentos prejudiciais à concorrência, os quais não seriam factíveis na ausência desse poder. Por isso mesmo, a concentração e o poder econômico passaram a ser objeto de estudos jurídicos e econômicos baseados na premissa de que a preservação da livre concorrência é um pressuposto ao desenvolvimento da economia e garantia da livre iniciativa. $\mathrm{O}$ direito econômico reconhece que a livre iniciativa, isoladamente considerada, não garante a manutenção da liberdade econômica ou o modelo de competição perfeita no mundo fático, ou seja, os modelos econômicos estão sujeitos a falhas estruturais cuja correção justifica a intervenção do Estado na economia. Neste artigo, abordamos as diversas correntes que defendem ou condenam a intervenção do estado na economia e sua regulação, em variados graus. A intervenção do Estado na economia tornou-se objeto de estudo e matéria legislativa em todo o mundo, seja na ordem legislativa interna, seja na esfera do direito público internacional, donde se destaca a Organização Mundial do Comércio - OMC e a Organização para a Cooperação e Desenvolvimento Econômico OCDE.
\end{abstract}

PALAVRAS-CHAVE: Concorrência; Objetivos; Livre iniciativa; Regulação.
ABSTRACT: The Brazilian Federal Constitution, once it adopted the principle of free enterprise for its economic order, also accepted the freedom to conduct a business as the basis for the establishment of the broader market competition among economic agents. However, as economic history shows, economic freedom brings with itself concentration of economic power in the hands of certain companies (or group of companies). Such a concentration of power is reputed a market failure derives because it enables such companies to adopt certain behaviors considered harmful to competition, which would not be feasible without such power. Therefore, concentration and economic power have become object of study of law and economics based on the premise that the preservation of free competition is an assumption for the economic development and guarantee of free enterprise. Economic law recognizes as a fact that free enterprise, taken in isolation, does not guarantee the sustenance of economic freedom or the model of perfect competition in the factual world; in other words, economic models are subject to structural failures whose correction justifies state intervention in economy. In this paper we discuss the various currents that advocate or condemn state intervention in the economy and its regulation, in varying degrees. State intervention in the economy has become the object of study and legislative matters in the world, whether in the internal legislative order or in the sphere of public international law, where stands the World Trade Organization - WTO and the Organization for Economic Cooperation and Development - OECD.

KEYWORDS: Competition; Objectives; Free enterprise; Regulation.

SUMÁRIO: Introdução. 1. O direito da concorrência e as políticas públicas. 1.1. Principais objetivos da política de concorrência. 1.2. Objetivos complementares da política de concorrência. 2. Interface entre política de concorrência e outras políticas públicas. 2.1. Possíveis conflitos entre múltiplos objetivos. 2.2. Instrumentos da política de concorrência. Considerações finais. Referências.

\section{INTRODUÇÃO}

A concorrência é descrita como o conjunto das relações sociojurídicas entre empresas, as quais disputam entre si a preferência dos clientes e consumidores com o objetivo individual de maximizar seus lucros e sua participação de mercado. Segundo o disposto no art. 170 da CF/88, a livre iniciativa é o fundamento da ordem econômica e a concorrência um dos seus princípios informadores, juntamente com a soberania nacional, propriedade privada, função social da propriedade, defesa do consumidor e meio ambiente, redução das desigualdades sociais, pleno

\footnotetext{
* Universidade Federal do Rio Grande do Sul.
} 
emprego e favorecimento da pequena empresa. Daí se depreende a tentativa do legislador em inserir diversos valores, que muitas vezes competem entre si, como norteadores da ordem econômica nacional.

A garantia da livre iniciativa visa garantir aos diversos concorrentes o direito de disputar a preferência do consumidor no mercado de produtos e serviços. Na busca pela preferência do consumidor, os agentes econômicos empregam certos comportamentos estratégicos, sendo alguns deles considerados abusivos e ilegais se o agente respectivo for detentor de poder de mercado.

Assim, a teoria do abuso de posição dominante representa a proibição legal às empresas que o detém (posição dominante) a manipulação de preços, quantidade e qualidade dos produtos e serviço ou a combinação desses elementos no mercado. A partir da definição legal, se consideram algumas formas de comportamento empresarial prejudiciais à concorrência e, como tais, caracterizadores de abuso concorrencial ou de poder econômico.

É a posição privilegiada do agente econômico na cadeia econômica que lhe garantirá o poder de mercado, o qual é caracterizado pela capacidade de adotar comportamento autônomo em face dos concorrentes e dos consumidores, sem deles sofrer retaliação econômica. O comportamento do agente não seria factível sem o poder de mercado. É certo que o menor preço é um dos elementos mais relevantes para a escolha do consumidor, mas não é a única.

O reconhecimento do abuso do poder de mercado como elemento disfuncional para a garantia da concorrência exigiu a necessidade de regulação de determinados comportamentos com vistas a preservar a concorrência, já que o modelo teórico de competição perfeita ${ }^{1}$ (MONTORO FILHO, 2008 p. X e XII), tal como inicialmente concebido pelo liberalismo econômico, não é encontrado no mundo fático. Segundo a escola liberal, no ambiente de competição perfeita, a diminuição da produção por uma firma seria imediatamente compensada pelo aumento da produção de seus competidores, na mesma medida, suprindo o mercando. Ocorre que a pressuposição de que os agentes econômicos se mantivessem pulverizados no mercado e incapazes de individualmente nele influir foi abandonada, daí surgindo o espaço para a regulação da concorrência na busca de soluções para as chamadas falhas estruturais ${ }^{2}$ do sistema (NUSDEO,

\footnotetext{
1 “A descoberta dessa propriedade de compatibilização do interesse individual com o interesse coletivo entusiasmou muitos economistas que a generalizaram e passaram a olhar o mundo real pela ótica de modelos de concorrência perfeita, por meio dos quais se demonstra, matematicamente, a eficiência alocativa dos mercados livres. Como decorrência dessa visão, surge a recomendação de que o governo deve ter a menor interferência possível no livre funcionamento dos mercados. Essa foi a primeira versão da moderna ideologia do Estado mínimo." (MONTORO FILHO, 2008 p. X e XII).

2 "5. O antitruste e a intervenção do Estado no domínio econômico. Conforme verificado, a ocorrência de falhas de mercado constitui uma das justificativas para a intervenção estatal no sistema econômico. Nesse sentido, está
} 
2002, p. 59 e 61), dentre as quais a concentração de poder passou receber especial atenção como objeto de estudo do direito. Nesse passo, a intervenção do Estado na economia visa garantir a concorrência como princípio informador da livre iniciativa, por sua vez fundamento da ordem constitucional $^{3}$ (MOSCOGLIATO, 2008, p. 68-69).

Tradicionalmente, a intervenção do estado na economia e a regulação da concorrência é dicotomizada em duas posições tradicionais: (i) intervenção do Estado como agente econômico e, (ii) como agente regulador da economia.

Sem analisar especificamente as diversas correntes que estudam a intervenção do estado na economia e sua regulação, em variados graus, o direito da concorrência tornou-se objeto de matéria legislativa em todo o mundo, seja na ordem legislativa interna, seja na esfera do direito público internacional - donde se destacam a Organização Mundial do Comércio (OMS) e a Organização para a Cooperação e Desenvolvimento Econômico (OCDE). A primeira tem por escopo celebração de acordos multilaterais entre seus Estados-Membros, os quais se comprometem a manutenção de um sistema comercial internacional aberto, justo e competitivo. O sistema até mesmo permite que os Estados-Membros tomem a iniciativa de cobrar impostos adicionais para produtos importados, destinados a compensar os danos causados pelo comércio desleal praticado pelo país exportador.

Embora a mais antiga legislação sobre a concorrência no mundo contemporâneo tenha sido adotada pelo Canadá, em 1889 por meio do Act for the prevention and suppression of combinations formed in restraint of trade, lei abrangente e destinada a regular desde a formação de cartéis até fusões, que veio a lume um ano antes do Sherman Act nos Estados Unidos da América, foi este país que cunhou o termo antitruste e desenvolveu estudos relacionados à disciplina do poder econômico. No direito consuetudinário, o trust é uma organização ou acordo por meio do qual a propriedade (incluindo bem imóveis e móveis, tangíveis e intangíveis) é administrada por uma pessoa (ou organização) em favor e beneficio

nas origens da ruptura do sistema liberal clássico de separação entre as esferas política e econômica, base para a emergência do direito econômico enquanto ramo destinado a implementar a política econômica do Estado. Como é sabido, a intervenção estatal na economia teve por base, além da ocorrência de imperfeições de mercado, a suscetibilidade do sistema capitalista a crises cíclicas, que não podiam ser solucionadas pelo simples jogo das forças do mercado. Com isso, o Estado Liberal passou a assumir paulatina e assistematicamente funções com relação å economia - não concebidas originalmente - voltadas å correção de tais crises. (p. 59)." (NUSDEO, 2002 , p. 59 e 61 )

3 “O estudo da correlação entre direito e economia não é novo e prêmio Nobel já foi concedido em razão de pesquisas e discussões sobre o tema. Por exemplo, Douglas C. North foi agraciado porque, entre outros motivos, desenvolveu trabalhos sobre a economia institucional, em que questões a respeito do conjunto das regras de uma sociedade e sua aplicação (enforcement) são tratadas para explicar porque alguns países são ricos e outros são pobres" (MOSCOGLIATO, 2008, p. 68-69). 
de outra. O termo antitrust passou ser sinônimo de direito concorrencial não porque o Sherman Act regulasse o instituto do trust propriamente dito, mas porque uma larga parcela das empresas americanas se valia do trust para ocultar a verdadeira natureza de sua estrutura negocial. Grandes trustes se tornaram sinônimo de monopólios, o que foi compreendido como uma ameaça à democracia e ao livre mercado, daí sua regulação pelo Sherman Act e Clayton Act. Este último, datado de 1914, foi aprovado para complementar o primeiro, listando diversas categorias específicas de condutas abusivas, inclusive a discriminação de preços (seção 2), negociação exclusiva (seção 3) e fusões que substancialmente diminuam a concorrência (seção 7).

Esses diplomas legais tiveram por objetivo vedar as restrições ao comércio, codificando regras já existentes no antigo sistema inglês e norte-americano da common law. A base histórica dessa legislação se depreende da analise do Standard Oil case ${ }^{4}$ (EUA, 1911), no qual o Chief Justice White expressamente vinculou o Sherman Act aos preceitos da common law e regulamentos ingleses do século XVI. ${ }^{5}$

A I Guerra Mundial vivida pelo mundo ocidental nas duas primeiras décadas do século XX provocou uma alteração na postura dos Estados em relação à economia, os quais passaram a regulá-la mais intensamente, numa tentativa de organizar uma economia de guerra. Já em 1929, no momento da grande crise do capitalismo norte-americano, o Estado assume a tarefa de impulsionar a economia intervindo diretamente em diversos setores, por meio da oferta de crédito, subsídios e incentivos, de tal forma que passa a ser o principal vetor do sistema econômico. Ao desempenhar essa nova função de direção da economia, o Estado se vale de instrumentos jurídicos para controlála, estimulá-la, dirigi-la e, ao mesmo tempo, permitir a liberdade de iniciativa ${ }^{6}$ (KONDER, 1965, p. 14-26). O Estado passa a conduzir o mercado por meio de técnicas de direção, utilizando-as para implementar políticas públicas.

\footnotetext{
${ }^{4}$ Standard Oil Co. of New Jersey v. United States, 221 U.S. 1 (1911), foi um caso em que a Suprema Corte dos Estados Unidos condenou a Standard Oil por monopolizar a indústria do petróleo por meio de uma série de ações abusivas e anticoncorrenciais. A solução do tribunal foi dividir a Standard Oil em várias empresas concorrentes. ${ }^{5}$ No caso Standard Oil Co. of New Jersey v. United States, 221 U.S. 1 (1911), a Suprema Corte dos Estados Unidos julgou a empresa culpada por monopolizar a indústria de petróleo por meio de uma série de condutas abusivas. A decisão foi a de dividir a Standard Oil em várias empresas geograficamente separadas e concorrentes entre si. A Corte empregou a mesma exegese das autoridades Inglesas para definir o termo "restrição do comércio" e concluiu que seu conceito aplica-se para contratos dos quais resultem "monopólios ou suas consequências", tais como elevação de preços, redução da produção e redução de qualidade. WIKIPEDIA. Revolução da $\quad$ Informação. $\quad$ Disponível <http://en.wikipedia.org/wiki/Standard_Oil_Company_of_New_Jersey_v._United_States〉. Acesso em: 12 ago. 2014.

${ }^{6}$ Esse novo papel do Estado na economia é visto como o nascimento do direito econômico como ramo do direito: "O conjunto das técnicas jurídicas de que lança mão o Estado contemporâneo na realização de sua política econômica”. (KONDER, 1965, p. 14-26)
} 
Também a legislação da União Europeia mantém pilares econômicos e sociais, sob os quais a defesa da concorrência é vista como elemento essencial à criação de um mercado comum livre de restrições ao comércio. A primeira provisão foi lançada no artigo 81 do Tratado da $\mathrm{EC}^{7}$, a qual regula os cartéis e acordos verticais restritivos do comércio. Já o artigo 82 do Tratado permite que o Conselho Europeu emita regulamentos para controlar fusões, sendo a concentração (fusão ou aquisição) analisada sob a ótica da dimensão da comunidade, ou seja, seus efeitos mais significantes sobre determinados Estados-Membros e efeitos impeditivos de uma efetiva concorrência. Essas regras estão agora renumeradas como artigos 101 e 102 do TFUE.

No Brasil, o direito da concorrência recebeu novo impulso a partir do advento da lei $8.484 / 94$, atualmente revogada pela vigente lei $\mathrm{n}^{\mathrm{o}} 12.529 / 11$. A lei de 94 foi o marco institucional no país para a institucionalização do CADE como autarquia, o que lhe dotou de poder de executar suas próprias decisões. Em seu mérito, a lei brasileira flexibiliza a vedação de atos de concentração que possam limitar ou de qualquer forma prejudicar a livre concorrência, ou resultar na dominação de mercados relevantes, permitindo sua aprovação pela autoridade concorrencial mediante avaliação do caso concreto e a obtenção de certas vantagens econômicas (art. $88, \S 5^{\circ}$ e $\S 6^{\circ}$ da Lei 12.529/11) que a justifiquem.

Após essa breve análise sobre a origem e objetivos gerais do direito da concorrência como princípio instrumentador da livre iniciativa, passamos a analisar os demais objetivos da política concorrencial que se depreendem das diretrizes à Ordem Econômica e Financeira dispostos no Titulo VII da Carta Magna.

\section{O DIREITO DA CONCORRÊNCIA E AS POLÍTICAS PÚBLICAS}

A disputa dos consumidores gera a concorrência entre agentes econômicos no mercado. Essa disputa, de caráter permanente, lhes impõe uma constante busca de vantagens competitivas para que seus bens e serviços sejam preferidos. Tais vantagens são denominadas de eficiência econômica ${ }^{8}$ (SALOMÃO FILHO, 2001, p. 110) e podem envolver todos os aspectos da atividade

\footnotetext{
${ }^{7}$ A regulamentação por nós encontrada aparece sob a abreviação de regulamento (CE) n. ${ }^{\circ} 1 / 2003$ do Conselho Europeu, de 16 de dezembro de 2002, relativo à execução das regras de concorrência estabelecidas nos artigos 81. ${ }^{\circ}$ e 82. ${ }^{\circ}$ do Tratado e Regulamento (CE) n. ${ }^{\circ}$ 139/2004 do Conselho Europeu, de 20 de janeiro de 2004, relativo ao controle das concentrações de empresas ("Regulamento das concentrações comunitárias") e Regulamento (CE) n. ${ }^{\circ}$ 802/2004 da Comissão, de 7 de abril de 2004, de execução do Regulamento (CE) n. ${ }^{\circ}$ 139/2004 do Conselho.

8 “A eficiência é o princípio fundamental do direito antitruste na teoria neoclássica. Para os neoclássicos mais exaltados, mais do que um dos elementos, a eficiência é o fator central a definir a licitude ou não do poder no
} 
empresarial, desde sua estrutura física e produtiva, técnicas de administração, até o desenvolvimento de produtos e novas tecnologias, além de técnicas de distribuição e atendimento pós-venda. O conceito de eficiência econômica tem posição central na teoria concorrencial. Representa os ganhos de produtividade dos agentes econômicos e as vantagens repassadas aos consumidores que, com ela, obtém maior variedade de produtos e serviços por preços mais baixos e com melhor qualidade.

O regime concorrencial promove o desenvolvimento econômico ao estimular a eficiência econômica sob a forma de inovações e mudanças tecnológicas. Os agentes econômicos, visando vencer a concorrência, vão alocar seus recursos econômicos e naturais para a produção mais eficiente possível de bens de maior valor agregado e que aumentam o bem-estar dos consumidores, pelos menores preços. Por isso se afirma que os preços praticados por determinadas empresas dominante num dado mercado são indicadores para que outras direcionem seus recursos para a produção de bens, em concorrência, visando obter uma parcela do mercado.

A eficiência econômica é, assim, acolhida pelo direito da concorrência como justificativa do crescimento da participação do agente econômico num dado mercado e mesmo a aquisição de posição de poder de mercado.

No Brasil, a aquisição de poder econômico não é ilícito per se, não obstante toda a forma de concentração econômica ${ }^{9}$ (BAGNOLI, 2005, p. 148-149) representar uma falha de mercado por permitir ao agente dominante a adoção de comportamento anticoncorrencial e economicamente significar a alocação ineficiente de recursos. De fato, a concentração de poder econômico é vista como uma contrariedade ao estímulo à eficiência dinâmica, a mudanças tecnológicas e ao progresso econômico, cuja consequência é o prejuízo e diminuição do bem-estar dos consumidores. A doutrina da regulação do mercado vem suprir suas falhas por meio de uma política da concorrência que se apresenta dicotomizada entre a (i) análise econômica ou da

mercado. Como se verá a seguir, a aplicação desse conceito pode levar a resultados economicamente indesejáveis e juridicamente insatisfatórios. A sua inclusão entre os instrumentos de política econômica explicase. Como já visto, a eficiência constitui-se em um dos maiores se não o maior motor de promoção de políticas econômicas de concentração de empresas.” (SALOMÃO FILHO, 2001, p. 110)

9 "Quando se fala em posição dominante entende-se a participação que determinada empresa tem num certo mercado. Esta participação pode ser resultado de sua eficiência concorrencial que lhe garantiu uma posição de destaque em decorrência da opção dos consumidores. Até então, nada há de anticoncorrencial. A antijuridicidade se apresenta se a empresa abusar de seu poder de mercado, ensejando a repressão (ou a prevenção, se o ato ainda não estiver consumado) das autoridades de defesa da concorrência." (BAGNOLI, 2005, p. 148-149) 
eficiência e a (ii) análise não-econômica ou de interesse público ${ }^{10}$ (SALOMÃO FILHO, 2001, p. 21-22), cada qual representando um valor em si.

Assim, para a verve que sustenta a abordagem econômica, a política da concorrência tem como objetivo exclusivo maximizar a eficiência econômica. Segundo essa visão, as políticas públicas da administração para a concorrência não admitem a escolha de objetivos sócio-políticos tais como a diminuição das desigualdades regionais e outros que foram designados na Carta brasileira, rejeitando-os como ínsitos à política da concorrência porquanto dependem de juízo de valor subjetivo e, por isso mesmo, impossíveis de serem consistentemente aplicados ao direito da concorrência.

A outra vertente, denominada de abordagem não econômica ou de interesse público, defende que a política de concorrência decorre de múltiplos valores, os quais não são facilmente quantificados nem podem ser exclusivamente representados e reduzidos ao conceito objetivo de eficiência econômica, isso porque a multiplicidade de valores refletidos em toda a cultura social e suas instituições devem ser recebidas como elementos de aplicação de defesa da concorrência. Ainda assim, no seio dessa escola, há variados pontos de vista quanto ao valor e importância a serem atribuído aos diferentes fatores envolvidos na defesa da concorrência, o que torna a questão bastante mais complexa.

Embora a política da concorrência se destine a corrigir as falhas de mercado ${ }^{11}$ (BAGNOLI, 2005, p. 152), o direito não poderá formular leis e regulamentos específicos para cada espécie de atividade econômica ou para cada uma das situações anticompetitivas, reais ou potenciais, existentes no mercado. É necessário encontrar meios viáveis de implementação da política da concorrência nos quais seja mantido o nível de regulação desejável ou eficiente para corrigi-las

\footnotetext{
10 “Tendo em vista a ampla definição de regulação apresentada, é possível revisitar ambas as escolas que tradicionalmente procuram estudar o funcionamento do Estado na economia, analisando-as criticamente dentro de um mesmo espectro teórico. ...

2.1 Escola do Interesse Público. A escolha da denominação "Escola do Interesse Público" é proposital. Ela evidencia o fato de que a justificativa para regulação, entendida no sentido amplo supradescrito, nada tem a ver com a preservação do mercado. O objetivo é a busca do bem público definido de formas diversas. (p. 16-17) 2.2. Escola Neoclássica ou Econômica da regulação. Origem do movimento de desregulamentação. Crítica. Sob a denominação genérica de Escola Econômica da regulação escondem-se várias tendências, com dois pontos fundamentais em comum: a negação de qualquer fundamento de interesse público na regulação e a afirmação do objetivo de substituição ou correção do mercado através da regulação.” (SALOMÃO FILHO, 2001, p. 21-22)

11 "O desestímulo ao ingresso dos novos entrantes se daria pelas barreiras a entrada, fatores existentes num mercado que colocam um potencial concorrente em desvantagem em relação aos agentes econômicos já estabelecidos, dentre os quais pode-se citar: (i) custos fixos elevados; (ii) custos irrecuperáveis ou afundados (sunk costs); (iii) barreiras legais ou regulatórias; (iv) recursos de propriedade das empresas instaladas; (v) economias de escala ou de escopo; (vi) grau de integração da cadeia produtiva; (vii) fidelidade dos consumidores as marcas; e (viii) a ameaça de reação dos competidores instalados." (BAGNOLI, 2005, p. 152)
} 
(falhas do mercado), criando uma estrutura jurídica legal e administrativa da qual a implementação dessa política dependerá.

É nesse ponto que se visualiza a intersecção entre o direito e a economia. Essa intersecção provoca uma tensão decorrente da defesa de diferentes conceitos e ideias econômicas sobre a matéria em face da necessidade de um conjunto de regras legais (as quais também possuem conteúdo econômico) para regular a matéria e avaliar os fatos jurídicos praticados pelos agentes no mercado. Normalmente, o direito econômico concorrencial faz essa avaliação por meio da análise dos atos (condutas) e contratos (estrutura ou contratos de fusões e aquisições) dos agentes no mercado, quando detentores de posição dominante ou que cuja contratação venha dar suporte econômico à sua aquisição.

O exemplo clássico para as diferentes concepções para a aplicação do direito da concorrência é a opção do legislador pela proibição absoluta para determinados comportamentos dos agentes econômicos (abordagem per se), em oposição a uma proibição relativa (regra da razão) ${ }^{12}$ (BRUNA, 1997, p. 154), considerando que certas práticas empresarias (a princípio reputadas anticompetitivas, tais como acordos de fixação de preços ou contratos de exclusividade), passam a ser admitidas em certas circunstâncias se a hipótese representar ganhos em eficiência e benefícios à sociedade.

Um segundo aspecto, no qual a intersecção entre valores jurídicos e econômicos se revela mais proeminente, é a controvérsia existente quanto a fixação da ordem de preferência ou prioridade a ser concedida entre a política de concorrência em face das demais políticas governamentais e que integram a Ordem Econômica e Financeira ${ }^{13}$ (NUSDEO, 2001, p. 198-199).

No Brasil a política da concorrência é um dos princípios informadores da Ordem Econômica - art. 170 da CF/88 - cujos fundamentos são a valorização do trabalho humano e a livre iniciativa ${ }^{14}$ (GRAU, 1991, p. 22). Assim, a livre inciativa está vinculada a múltiplos princípios fixados nos diversos incisos da norma constitucional.

\footnotetext{
12 "Segundo a regra da ilegalidade per se, alguns tipos de conduta - tais como algumas espécies de acordos entre concorrentes - são consideradas ilícitas, independentemente do contexto em que forem praticadas, ou mesmo dos efeitos obtidos, sejam eles danosos ou benéficos à concorrência. [...] Já em relação às práticas sujeitas à regra da razão, o acusado é admitido a demonstrar que tais práticas geram ganhos de eficiência e que os danos à concorrência são mínimos. Sob esse prisma, a prática somente é considerada ilícita na medida em que configura uma restrição não razoável (ou desarrazoada) à concorrência....”. (BRUNA, 1997, p. 154)

${ }^{13}$ Sobre a matéria vide NUSDEO, 1994, p. 198-199.

14 “A Constituição, menciona a livre iniciativa, tanto no art. $1^{\circ}$., IV, quanto no art. 170, caput.

Livre iniciativa é termo de conceito extremamente amplo. Não obstante, a inserção da expressão no art. 170 , caput, tem conduzido à conclusão, restrita, de que toda a livre iniciativa se esgota na liberdade econômica ou de iniciativa econômica. Dela - da livre iniciativa - se deve dizer, inicialmente, que expressa desdobramento da liberdade." (p. 221). (GRAU, 1991, p. 22)
} 
Tendo em vista a ordem constitucional vigente, será necessária a integração da política de concorrência com os demais princípios que perfazem a ordem econômica, os quais igualmente demandam políticas governamentais. Exemplos de políticas econômicas complementares à concorrência são as iniciativas voltadas para a desregulamentação e a privatização de empresas estatais, a política de desenvolvimento regional ou a defesa do meio ambiente. Entretanto, determinadas políticas públicas podem apresentarem-se contrárias à ordem concorrencial stricto sensu quando privilegiam um dos princípios constitucionais informadores da livre iniciativa em detrimento dos demais. É o caso, por exemplo, de uma política de busca do pleno emprego em face da maximização do princípio da eficiência econômica que não leve em consideração a defesa do meio ambiente ou a defesa dos consumidores. Essa é a razão pela qual a aplicação de uma lei geral de defesa da concorrência poderá gerar conflito de interesses entre os vários setores da economia.

Verifica-se que na maioria dos países ocidentais industrializados a execução da política da concorrência é expressão de uma legislação de ordem geral, a qual fixa os princípios informadores para aplicação em todos os setores da atividade econômica, salvo os casos de isenções especiais.

Nesse sentido, é necessário examinar a que se destina a política da concorrência.

\subsection{Principais Objetivos da Política de Concorrência}

A legislação de defesa da concorrência no Brasil como efetiva implementação do sistema de livre iniciativa e defesa da concorrência, é mais de um século posterior à introdução de leis antitrust pelo Canadá e os Estados Unidos em 1889 e 1890, respectivamente. As adoções dessas ideias por diferentes países correspondem a diferentes objetivos à política de concorrência sem que, no entanto, se deixe perder de vista a existência da ideia central expressada pela garantia e manutenção do processo competitivo, por meio da livre concorrência ou a proteção da concorrência eficaz.

O objetivo fundamental de manutenção do processo competitivo por meio da livre concorrência tem como suporte jurídico uma lei geral e estrutura administrativa organizada destinada à sua promoção e repressão a restrições inaceitáveis (atos e contratos). Desse objetivo fundamental decorrem propósitos imediatos, os quais podem ser assim classificados: $i$ ) a liberdade de comércio, ii) a liberdade de escolha e iii) acesso aos mercados.

Historicamente, a eficaz manutenção e promoção da defesa da concorrência significava combater as restrições privadas abusivas à competição, como forma de se garantir o necessário 
pluralismo econômico, ou seja, buscar, tanto quanto possível, uma estrutura econômica difusa e descentralizada. Esse pluralismo reflete o reconhecimento de que a concentração do poder econômico é uma ameaça à desejável descentralização desse poder, o que é a base da democracia econômica. Por essa razão, a maioria das legislações concorrenciais enfatizarem a proibição de acordos de fixação de preços e o abuso da posição dominante de mercado.

Inicialmente, essa preocupação determinou a tendência à proteção do pequeno negócio cuja subsistência, muitas vezes, depende da eliminação (ou regulação) dos conflitos gerados pelo poder das grandes empresas e os objetivos da maximização da eficiência econômica e do bem-estar do consumidor. Posteriormente, e em especial nas últimas décadas do século $\mathrm{XX}$, o papel da política de concorrência ampliou-se, passando a incluir novos paradigmas entre seus objetivos, tais como a redução da intervenção do governo no mercado (privatizações), a redução da pobreza (inclusão social), sustentabilidade econômica em face do meio ambiente ${ }^{15}$ (SABADELL, 2006, p. 16-17) e defesa do consumidor.

A lei brasileira concede à concorrência o status de bem imaterial e coletivo, inclusive submetendo ao seu domínio de aplicação o próprio Estado e suas empresas (estatais e de economia mista - vide art. 31 da LDC). Além disso, aplica-se a lei de defesa da concorrência não somente as práticas cometidas no todo ou em parte no território nacional, mas também a práticas (noutra ordem jurídica), mas que aqui produzam ou possam produzir efeitos. Trata-se da internacionalização dos efeitos da lei (vide art. $2^{\circ}$ da LDC), o que significa que mesmo agentes econômicos não sediados no país sujeitam-se a lei nacional se os efeitos do ato anticoncorrencial aqui ocorrerem.

Além disso, os vários órgãos responsáveis pela administração da política econômica nas diferentes jurisdições adotam variadas formas de defesa da concorrência: privatização, redução de tarifas alfandegárias, eliminação de cotas e licenças, entre outras, mas sempre com o objetivo de privilegiar a concorrência e reduzir as barreiras de entrada nos mercados, ampliando ao máximo seu acesso ao maior número possível de agentes concorrenciais.

Via de regra as autoridades encarregadas da jurisdição concorrencial não são as mesmas incumbidas da implementação direta das políticas comerciais ou de desregulamentação e abertura do mercado. Entendemos que aquela autoridade deveria exercer participação intergovernamental

\footnotetext{
15 "A crise do modelo estatista afeta os modelos de tutela ambiental. A ausência de vontade e/ou capacidade dos aparelhos O Estado cria e impõe as regras, exprimindo o bem comum ou o interesse geral de preservação da qualidade ambiental) em favor de modelos mais flexíveis, centrados em negociações entre agências públicas e atores do mercado (visão mercadocêntrica).” (SABADELL, 2006, p. 16-17)
} 
no desenvolvimento e aplicação das políticas públicas antitruste, seja porque realizam os julgamentos e intervenções nesse campo, seja porque as autoridades da concorrência são tecnicamente habilitadas para sugerir a implementação de políticas e soluções de mercado.

Há também a questão do estímulo e proteção governamental aos monopólios estatais. Esses monopólios são normalmente justificados pela necessidade de se garantir tal posição como instrumento de melhoria da competitividade da empresa (ou setor econômico), desempenho ou bem-estar social. São clássicos exemplos de monopólios estatais as empresas prestadoras de serviços públicos e/ou sociedades mistas que desenvolvem atividades tipicamente privadas as quais são, muitas vezes, grandes empresas que orgulham a nação, mas que permanecem protegidas dos efeitos da concorrência. Há evidências de que tais empresas tendem a responder de forma insatisfatória aos mercados e a retardar melhorias na produtividade, além de representarem prejuízo da concorrência em seus mercados internos.

Em face do alargamento dos objetivos atribuídos ao direito da concorrência para além dos limites tradicionalmente formulados como a "defesa da concorrência", sua implementação já não se contenta com a simples aplicação da legislação destinada a corrigir atos de violação da concorrência ou acordos anticoncorrenciais. Em face do alargamento dos objetivos atribuídos ao direito da concorrência para além dos limites tradicionalmente formulados como a "defesa da concorrência", sua implementação já não se contenta com o controle dos atos de concentração ou condutas anticoncorrenciais, passando a exigir a aplicação de todos os princípios informadores da ordem econômica arrolados nos incisos do art. 170 da CF.

Diga-se que a prevenção do abuso do poder econômico é também um objetivo da política da concorrência. A prevenção concorrencial se dá por meio do controle da conduta dos agentes econômicos e dos atos de concentração, visando garantir a liberdade de acesso aos mercados livre de barreiras e monopólios, atendendo aos consumidores uma maior eficiência econômica.

A defesa do consumidor como princípio da ordem econômica é bastante justificada pela aplicação do conceito de eficiência econômica destinado a maximização de seu bem-estar. A ideia aparece claramente nas Diretrizes para Aplicação da Lei Antitruste do Departamento de Justiça dos EUA (1988), segundo a qual seu propósito é estabelecer princípios abrangentes de concorrência, formulados para assegurar uma interação irrestrita das forças competitivas de forma a estimular a melhor distribuição de recursos, preços mais baixos e maior qualidade de produtos e serviços para os consumidores. 
Como visto, há vários propósitos para o direito da concorrência e sua coexistência na ordem legal não encerra em si ordem de prioridade ou classificação, permitindo aos agentes encarregados de sua defesa e da administração pública uma justaposição de princípios e fundamentações. Por isso, os diferentes princípios aplicáveis à defesa da concorrência incitam os estudiosos a questionar quais deles seriam efetivamente válidos e justificáveis para implementar a legislação e política da concorrência.

A teoria da eficiência econômica é a mais citada e a mais difícil de ser conceituada na doutrina concorrencial. Essa teoria vem sendo empregada nas decisões para a matéria de antitrust pela Suprema Corte dos Estados Unidos e órgãos administrativos desde os anos 70. Também a autoridade concorrencial brasileira dela se vale, e ainda que não esteja positivada nem nenhum texto legal, a eficiência econômica representa um verdadeiro sobrevalor presente na ordem legal.

Nesse ponto, passamos a abordar os objetivos ancilares da politica da concorrência.

\subsection{Objetivos complementares da Política de Concorrência}

Além de buscar a eficiência econômica e o bem estar do consumidor ${ }^{16}$ (GOLDBERG, 2006, p. 98-99), a economia capitalista trouxe perspectivas à vida social e econômica, as quais agregaram novos propósitos a política da concorrência, dentre os quais cita-se a proteção às pequenas empresas, manutenção da justiça econômica, igualdade socioeconômica regional, defesa do meio ambiente. Objetivos outros tais como o controle da inflação também podem ser inseridos entre seus propósitos.

Objetivos defendidos como política de concorrência são: o reconhecimento (e regulação) dos efeitos gerados por atos de concentração (fusões e aquisições) sobre o emprego e a continuidade e desenvolvimento de comunidades regionais. Isso porque tais atos tendem a reorganizar as unidades produtivas com o consequente deslocamento da escolha das fontes de matéria-prima utilizadas e alteração da produção e distribuição dos produtos. Até mesmo as decisões administrativas e

\footnotetext{
${ }^{16}$ A idéia de que a eficiência alocativa deveria ser o objetivo central da política antitruste, como vimos, decorre da intuição de que o papel desse tipo de política pública é a maximizadora de riqueza e do bem-estar. E, como o poder de mercado pode destruir riqueza (uma vez mais, os triângulos de peso-morto), o papel da política antitruste é mitigar as possibilidades de que venha a ser exercido de forma abusiva. Por conta desse tipo de abordagem, as preocupações da política antritruste foram em um primeiro momento confinadas à eficiência econômica e suas propriedades, de caráter estático". (GOLDBERG, 2006, p. 98-99)
} 
financeiras são deslocadas por meio de um processo de despersonalização da propriedade da empresa e um distanciamento dos órgãos decisores da sede produtiva.

A ordem de importância a ser conferida a esses diversos objetivos identificados como propulsores do direito da concorrência são questões em permanente debate e contradição entre os teóricos. O que se observa é que há dois pontos que apresentam certa convergência na doutrina e em proposições legislativas:

a) O objetivo primeiro da política de concorrência é proteger a própria concorrência (e não o concorrente, o qual fica exposto à concorrência) ${ }^{17}$ (FORGIONI, 2007, p. 71), eliminando ou evitando práticas restritivas de empresas privadas e públicas que interfiram de forma imprópria e desfavorável no processo competitivo. Diz-se que o processo competitivo não existe como um valor intrínseco esgotado em si mesmo, mas sim como meio ou instrumento de atingimento de outros objetivos.

b) No sentido inverso, há correntes doutrinárias que se opõem à existência de qualquer tipo de restrição privada à concorrência, fomentando ainda mais a importância do estudo dos vários objetivos possíveis para o direito da concorrência.

Sem prejuízo do direito da concorrência ser reconhecido como o responsável pela instauração de um processo estimulador ao uso eficaz e alocação eficiente dos recursos econômicos e sociais, a forma como deve ser implantada e a hierarquia desses propósitos não é uniformemente aceita. $\mathrm{O}$ que se vê é que há diferentes posicionamentos a respeito dos objetivos da concorrência e de uma possível precedência hierárquica de algum deles.

Em linhas gerais, vemos que a cultura da concorrência exige estudos aprofundados para a identificação e classificação de seus objetivos econômicos, sociais e políticos, além da distribuição equilibrada de pesos entre a eficiência econômica e os vários outros objetivos econômicos e sociais que lhe são atribuídos.

\footnotetext{
17 “retornamos, então, ao problema que muito já foi referido: a concorrência, é cediço, prejudica os concorrentes, mas esses prejuízos podem ser licitamente causados, desde que resultantes "de processo natural fundado na maior eficiência do agente econômico em relação a seus competidores". (FORGIONI, 2007, p. 71)
} 


\section{INTERFACE ENTRE POLÍTICA DE CONCORRÊNCIA E OUTRAS POLÍTICAS PÚBLICAS}

A lei de defesa da concorrência funciona como uma ordem central para o direito econômico ou como elemento central no subsistema da legislação econômica. É lei de aplicação geral a todos os setores da atividade econômica, salvo aqueles abrangidos por isenções especiais.

São diversas as políticas púbicas que podem influir no estado da política de concorrência, o que conduz a uma necessária interferência entre a política da concorrência e outras políticas públicas, o que determina até mesmo a extensão e limites em que os objetivos da política de concorrência são traçados, sem representar conflito com essas “outras” políticas públicas.

Dentre as políticas governamentais que podem influenciam a política de concorrência estão as políticas de comércio exterior (taxas alfandegárias, cotas, subsídios, ações antidumping, regulamentação do conteúdo doméstico e restrições às exportações), industrial, de desenvolvimento regional, política de propriedade intelectual, política de privatização e reformas reguladoras, de ciência e tecnologia, política fiscal, entre outras. A questão que se apresenta é definir a prioridade dos propósitos da política de concorrência no sistema geral das políticas governamentais à implementação da Ordem Econômica Constitucional.

De fato, pode-se defender mesmo que a política de concorrência seja vista como o quarto alicerce do sistema de políticas econômicas de determinado governo, ao lado das políticas monetária, fiscal e de comércio exterior.

\subsection{Possíveis conflitos entre múltiplos objetivos}

O núcleo central da legislação concorrencial é a manutenção ou proteção da concorrência por meio da prevenção de restrições privadas ao comércio e do abuso do poder econômico.

Entretanto, os múltiplos objetivos da política de concorrência não se encontram organizados em princípios definidos ou sedimentados na cultura jurídica. No caso brasileiro, a Constituição Federal evidencia a tentativa de englobar múltiplos objetivos articuladores da livre iniciativa empresarial, dentre eles a gestão da política de concorrência. Inevitavelmente, essa escolha constitucional tende a gerar disputas e resultados discrepantes na aplicação da lei, pois os diversos objetivos perseguidos muitas vezes colidem e apresentam antagonismos intrínsecos em conteúdo e, 
em muitas situações, a persecução de um objetivo exclui os demais ${ }^{18}$ (SALOMÃO FILHO, 2001, p. 131-132).

De outro modo, o fato de a política da concorrência admitir múltiplas proposições e alternâncias em seus propósitos prova que o direito da concorrência pode se adaptar às mudanças das condições políticas, sociais e econômicas que procura regular. Assim, para viabilizar a proteção e eficácia aos diversos propósitos visados pela ordem constitucional, a implementação da política da concorrência no país exige uma concepção pluralista a respeito das metas a serem atingidas, as quais vão muito além da tradicional prevenção de restrições privadas ao comércio e vedação aos abusos do poder econômico.

Nesse ponto, por exemplo, a política de proteção às pequenas empresas ${ }^{19}$ (SILVA, 2001, p. 250-251) e a busca do pleno emprego poderá colidir com a obtenção da máxima eficiência econômica, pois nem sempre políticas de proteção daquelas empresas e/ou pleno emprego representaram a meios mais eficientes para produção de bens do ponto de vista econômico.

O que não poderá ocorrer é permitirmos que o sistema de defesa da concorrência seja cooptado por um ou mais grupos sociais os quais, clamando em nome da proteção da concorrência estejam, na verdade, solicitando a sua proteção em face da concorrência, levando o sistema a uma contradição: no exemplo dado, o propósito de proteção das pequenas empresas não poderá representar a proteção dessas pequenas empresas (os concorrentes), mas sim a proteção à defesa da própria concorrência.

Outros objetivos da política concorrencial, tais como a garantia de igualdade econômica entre diferentes regiões de um país apresenta graus diversos de incompatibilidade técnica com a defesa da concorrência, tendo em vista as dificuldades em definir corretamente o impacto e os

\footnotetext{
18 "No sistema brasileiro os limites da atuação do estado no estabelecimento e execução da política industrial vem estabelecidos no art. 174, caput, da Constituição Federal. Ali se atribui ao Estado a função de regulamentação da atividade econômica. Exceção e feita ao planejamento econômico, cujas regras são determinantes para o setor público, mas meramente indicativas para o setor privado. Com essa frase final o constituinte procurou afastar a possibilidade de dirigismo estatal da economia. Esse tipo de afirmação, no entanto, pouco ou nada esclarece a respeito da amplitude da discricionariedade do Estado na fixação da política industrial. Afastado o dirigismo, é necessário determinar a forma de intervencionismo propugnada pelo constituinte brasileiro. Para essa definição o art. 174, supramencionado, é de pouco auxilio." (SALOMÃO FILHO, 2001, p. 131-132)

19 "Todavia, alerta LUIZ S. CABRAL DE MONCADA que o apoio às microempresas e empresas de pequeno porte não se confunde com a prevenção e repressão dos desvios da concorrência. São diferentes os objetos da proteção respectiva e o tipo de atividade que a Administração Pública leva a cabo nas duas situações. Segundo ele, a política de defesa da concorrência, já tradicional em quase todos os países ocidentais, só aceita a intervenção estatal em casos limites, suscetíveis de bloquear o funcionamento do sistema econômico vigente." (SILVA, 2001, p. 250-251)
} 
efeitos das atividades econômicas junto a essas comunidades. O mesmo poderá ocorrer quando os objetivos da política concorrencial sejam a justiça, equidade, pluralismo etc.

As tentativas de incorporar tantos objetivos na política da concorrência tende a gerar uma interpretação incorreta e o desvirtuamento de sua aplicação. Torna-se pouco provável que um arcabouço legislativo expresse padrões claros e economicamente precisos de comportamento no mercado concorrencial ao tentar alcançar objetivos diversos. Ao contrário, leis dessa natureza podem gerar distorções no mercado e o enfraquecimento do processo concorrencial.

De todo modo, é bastante clara a tendência para que o direito da concorrência e as políticas públicas respectivas abranjam objetivos diversos da eficiência econômica e da correta alocação de recursos, atendendo interesses públicos em sentido amplo, passando a incorporar fins metajurídicos ou sociopolíticos.

Economia e Direito ${ }^{20}$ (PINHEIRO; SADDI, 2006, p. 12-16) (CALIENDO, 2008, p. 77) compartilham determinados fenômenos sociais como objeto de estudo científico, mas nem por isso se poderá afirmar que a economia seja revela por força da lei nem que a lei deva expressar a atividade econômica. Não obstante o valor da análise econômica como fonte de valiosas percepções sobre a dinâmica e funcionamento das empresas no mercado, os prováveis efeitos de determinadas práticas comerciais ou a antecipação do comportamento dos agentes econômicos em certas circunstâncias, o fato é que os estudos ou conclusões em matéria de análise econômica do direito não são leis (e, se transformadas em leis, tais análises e conclusões econômicas passam a integrar o jus positivo).

Na própria ciência econômica se identifica intenso debate a respeito do tipo de estrutura de mercado que melhor garantirá a eficiência e dinamismo econômico. Os próprios economistas não são unânimes quanto a carga máxima de tributação admitida para preservar ganhos de eficiência econômica, os meios mais adequados para alcançar a distribuição de renda e a maximização do bem estar do consumidor ou o bem estar econômico total.

Há circunstâncias em que a busca da eficiência econômica gera, ao mesmo tempo, aumento de superávit do consumidor e do produtor, tudo em consequência dos níveis mais elevados de produção por preços iguais ou mais baixos. Nessas situações poderá haver maiores lucros para as

20 "Como o direito pode encorajar a eficiência nas transações? O direito realiza essa tarefa por diversos meios, dentre os quais podemos destacar: i) corrigindo ou prevenindo as falhas de mercado (market failure), assim, por exemplo, quando o direito estabelece regras jurídicas que evitam o surgimento de monopólios ou cartéis lesivos à eficiência geral do sistema; ii) garantindo a previsibilidade e o cumprimento de promessas negociais ou iii) regulando as externalidades, ou seja, os custos que não são diretamente refletidos nos preços dos bens e que são transferidos para terceiros de modo involuntário. Um exemplo de externalidade pode ser encontrato nos custos ambientais de produtos poluentes". (PINHEIRO; SADDI, 2006, p. 12-16) 
empresas, caso em que os defensores da aplicação da eficiência econômica teriam pontos de vista coincidentes com aqueles que admites outros propósitos para o direito da concorrência, considerando o equilíbrio da situação econômica e a distribuição dos benefícios para produtores e consumidores.

As disputas surgem quando o superávit do produtor aumenta às custas do superávit do consumidor, ainda que o superávit total aumente ${ }^{21}$ (bem-estar econômico da sociedade) (FANCESCHINI, 2004, p. 267-268). Essas situações geram controvérsias sobre a atribuição de efeitos pró-competitivos ou anticompetitivos de uma certa situação, embora a regra geral aplicada à política de concorrência dê maior importância ao superávit do consumidor.

Sem embargo do dissenso encontrado na opinião dos economistas (o que, aliás, se verifica em outras ciências), é amplamente aceito que o emprego da análise econômica confere um grau mais elevado de precisão e previsibilidade na aplicação da política de concorrência, daí decorrendo seu prestígio como instrumento de análise eminentemente econômica, usada para avaliar situações jurídico-concorrenciais. Cita-se, entre outros, a análise dos efeitos econômicos de determinadas práticas negociais, sua justiça, equidade ou seu impacto na estrutura do mercado. Por isso afirma-se que a política da concorrência incorpora tanto princípios jurídicos quanto econômicos, e ambas as disciplinas desempenham papéis complementares.

A aplicação da Lei $n^{o} 12.529 / 11^{22}$ (DIMOULIS, 2004, p. 147-148) exige a definição do conceito de interesse público, cuja natureza aberta e indeterminada - e sem pretender exaurir sua definição em todos os seus múltiplos aspectos - nos permite afirmar que interesse público serve à defesa de interesses segmentados, definindo como "público" certos direitos em certas situações (embora não em outras), dada a complexidade da abordagem do tema na política de concorrência.

O chamado interesse público é constantemente invocado pelos diversos participantes de mercado, cada qual reunido em grupos de interesse próprios, sempre na tentativa de submeter a política da concorrência a um processo político que, ao fim e ao cabo, visa garantir os interesses

\footnotetext{
21 "Em face das dificuldades de mensuração das eficiências, dada sua natureza conjectural, na análise de atos de concentração, antes de obstá-los, deve-se dar maiores ênfases às condutas infrativas pós-concentração, porque estas sim tendem a aumentar os custos dos concorrentes, gerando um efeito anticompetitivo nocivo pelo desestímulo que representa aos investimentos em eficiência inovativa e produtiva". (FANCESCHINI, 2004, p. 267-268)

22 "O ordenamento jurídico brasileiro, como praticamente todos os sistemas jurídicos modernos, adota a concepção coletivista-estatista da concorrência mediante restrições impostas na Constituição e na legislação sobre a concorrência. Por essa razão, devemos abandonar as visões ideológicas ditadas pelo neoliberalismo e perceber a livre concorrência não como liberdade de agentes econômicos, e sim como sistema extremamente complexo e coercitivo, que permite a ação econômica dentro de espaços criados e administrados por órgãos estatais." (DIMOULIS, 2004, p. 147-148)
} 
específicos desses grupos sobre critérios técnicos de implementação da política de concorrência e seus mecanismos de funcionamento. Aqui há o risco dos objetivos da política da concorrência serem subsumidos aos interesses particulares de grupos de pressão, como parte do processo político-social, ainda que em nome do interesse público. É a chamada captura do órgão regulador.

Nota-se que a execução da política da concorrência - ao conceber a análise do equilíbrio dos diferentes objetivos políticos, sociais e econômicos que correspondem aos diversos objetivos propostos pela Carta Magna - poderá ter sua independência facilmente subvertida no curso do processo político de implementação.

\subsection{Instrumentos da política de concorrência}

Há duas categorias clássicas de instrumentos aplicáveis à implementação da política de concorrência: a) estruturais e, b) comportamentais ${ }^{23}$ (conduta) (PINHEIRO; SADDI, 2006, p. 373). Esses dois instrumentos de análise da concorrência podem ser empregados isoladamente, sem que deles se afaste sua natural correlação, a qual resta evidenciada quando percebemos que certos comportamentos só serão considerados abusivos se o agente econômico já for titular de dominação no mercado.

Os instrumentos estruturais estão vinculados às fusões, aos monopólios ou ao domínio exercido pelas empresas em função de sua posição no mercado já ser dominante ou vir a ser a partir alterações em sua estrutura. Os instrumentos de análise orientados pela conduta igualmente pressupõem a existência de poder de mercado do agente econômico e analisam certos comportamentos e práticas empresariais, especialmente aqueles relativos a manipulação de preços e restrições verticais.

Em se tratando de cartéis $^{24}$ (GABAN; DOMINGUES, 2009, p. 163-164) há uma convergência de pontos de vista dos estudiosos sobre os objetivos da política de concorrência no sentido de condená-los inteiramente como conduta anticoncorrencial. Cartéis são acordos entre agentes econômicos reconhecidos como tentativas de reproduzir a prática monopolista de manipular os preços para níveis acima do competitivo, muitas vezes por meio da redução da produção.

\footnotetext{
23 "As condutas anticompetitivas dividem-se em horizontais e verticais, e conforme sejam voltadas para reduzir a rivalidade entre as empresas já instaladas ou alterar a estrutura do mercado, expulsando empresas já existentes ou dificultando novas entradas". (PINHEIRO; SADDI, 2006, p. 373)

${ }^{24}$ Sobre a matéria vide GABAN; DOMINGUES, 2009, p. 163-164.
} 
A conduta cartelizada implica naquilo que a ciência econômica denomina de "má alocação de recursos" e "redução do bem-estar econômico", práticas condenadas pela maioria dos economistas e estudiosos da política da concorrência. O cartel se apresenta no mercado sob diversas formas, sendo a fixação de padrão de preços sua expressão mais comum, embora sua definição abranja qualquer forma de acordos conspirativos, inclusive acordos destinados a fraudar licitações (cartelização de preços) e quaisquer tipos de conluio sobre preços entre concorrentes.

Visando atacar cartéis de fixação de preço $^{25}$ e elidir tal conduta do cenário econômico, há diferentes padrões legais e econômicos que podem ser adotados, como podemos verificar em diferentes jurisdições. Na União Europeia, França, Alemanha (GONÇALVES, 2002, p. 261-262) e

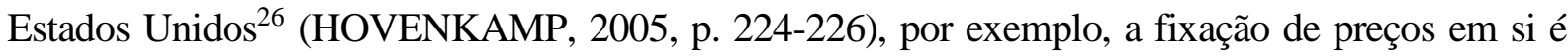
considerada ilegal (condenação per se) do ponto de vista concorrencial e está sujeita a punições do direito penal.

Há outros comportamentos da conduta empresarial objeto de análise concorrencial, em especial as chamadas restrições verticais, as quais se apresentam sob diversas formas, entre ela pode-se apontar: a) manutenção de preço de revenda ${ }^{27}$; b) venda vinculada (casada); c) exclusividade de distribuição ${ }^{28}$ e restrições geográficas de mercado ${ }^{29}$.

A análise de condutas abusivas deverá se concentrar nos padrões econômicos e legais aplicáveis a tais práticas. Entretanto, certos economistas defendem a análise das condutas abusivas por meio da aplicação do critério da motivação às restrições verticais ${ }^{30}$ (SALOMÃO FILHO, 1998, p. 279), enquanto outros defendem a aplicação dos critérios da eficiência e redução da concorrência, dependendo das situações específicas.

As diferenças de abordagem das restrições verticais persistirem, menos por causa da diversidade dos padrões legais e econômicos aplicáveis, e mais em face das justificativas filosóficas dos propósitos da política de concorrência. Os ordenamentos jurídicos para defesa da concorrência ora dão maior ênfase à liberdade de ação econômica para os participantes individuais

\footnotetext{
${ }^{25}$ Nesse sentido a decisão do CADE 08012.004372/2000-70 - Processo Administrativo.

26 "The basic judicial rule concerning resale price maintenance is clear. It is illegal per se, whether or not the defendant had market power, and regardless of the defendant's motives, such as the need to combat free riding. The Supreme Court reaffirmed this rule recently as 1984 in Monsanto Co. v. Spray-Rite Service Corp., 465 U.S. 752, 104 S. Ct. 1464 (1984). However, the per se rule against RPM is subject to two important judicially-created exceptions. The Colgate Exceptions for "Unilateral” RPM." (HOVENKAMP, 2005, p. 224-226).

${ }^{27}$ Nesse sentido a decisão do CADE 08012.003068/2001-11 - Processo Administrativo.

${ }^{28}$ Processo administrativo CADE 08012.008358/2002-23.

${ }^{29}$ Processo administrativo CADE 08012.012377/2007-69.

30 “As concentrações verticais só podem encontrar justificativa a partir de uma análise dos custos das transações (transction costs).”Vide SALOMÃO FILHO, 1998, p. 279.
} 
de mercado, ora afirmam que as restrições verticais são consideradas conflituosas com o principal objetivo da política, a defesa do mercado concorrencial.

A dominação do mercado não é ilegal nem a lei de defesa da concorrência visa elidir formas de dominação de mercado. Ao contrário, em havendo eficiência econômica a dominação do mercado estará plenamente justificada. Assim, a aplicação dos instrumentos de análise da estrutura jurídica e econômica dos agentes no mercado visa determinar a extensão do poder de mercado em jogo para, em consequência, analisar a legalidade de uma conduta ou de ato de concentração. Como dito antes, é o poder e domínio do mercado que autorizam os agentes detentores a práticas abusivas. É por essa razão que certas condutas especificamente descritas na lei - se e quando praticados por agentes econômicos detentor de poder de mercado - se sujeitam à investigação e à correção - art. 36 da Lei no 12.529/11.

Dentre as condutas incluídas no elenco de práticas consideradas anticoncorrenciais encontrase a fixação de preços predatórios, acesso privilegiado a canais de distribuição ou a certos bens ou matérias-primas escassa, condutas essas que - se praticadas por agentes econômicos detentores de poder de mercado - são presumidas como destinadas a alijar o concorrente do mercado ou a restringir-lhe o acesso.

Tais condutas precisam ser examinadas percucientemente, pois sua prática não é um ilícito per $s^{31}$ (SALOMÃO FIHO, 2002, p. 71), ou seja, a conduta sob exame poderá estar integrada a uma estratégia empresarial legítima, projetada para obter vantagem competitiva, e não para restringir a concorrência. Entretanto, é sabido que há uma divisão tênue entre o uso e o abuso do poder econômico. Certa prática posta em ação por empresa em posição dominante no mercado poderá (ou não) ser fruto de um desempenho competitivo superior e caracterizar (ou não) abuso de poder econômico.

Relativamente às fusões de empresa e à fixação de objetivos e instrumentos de política da concorrência, são apresentadas divergências significativas, pois normalmente haverá mais de um motivo para justificar a decisão da empresa à expansão por meio da aquisição de uma concorrente existente e operativa e não por meio do crescimento interno e orgânico a ser gerado a partir de novos investimentos.

Em se tratando de fusões horizontais ${ }^{32}$ (entre empresas concorrentes na mesma etapa do processo econômico), a investigação a ser feita pelas autoridades concorrenciais deverá avaliar o

\footnotetext{
${ }^{31}$ Sobre a regra da razão vide SALOMÃO FILHO, 2002, p. 71.

${ }^{32}$ Nesse sentido julga o CADE processo administrativo $\mathrm{n}^{\mathrm{a}}$ 08012.000074/2002-99.
} 
aumento do poder de mercado e/ou de eficiência econômica que a fusão resultará, sendo essa uma análise bastante complexa e, por vezes, controversa.

Usualmente há dois tipos de análise política para controlar o poder de mercado derivado de fusões horizontais: a) abordagem estrutural e, b) abordagem custo-benefício. Nem sempre será fácil distinguir perfeitamente uma e outra abordagem, pois há uma interação entre estrutura de mercado e conduta empresarial, sendo que a abordagem estrutural vale-se de um teste de concorrência que verifica se os maiores níveis de concentração resultantes da fusão podem dar margem a uma redução considerável da concorrência. Por meio dessa abordagem tenta-se evitar que as grandes empresas realizem práticas negociais anticompetitivas, preservando-se um ambiente não-concentrado. A fusão seria vetada porque sua aprovação resultaria numa empresa cujas dimensões ultrapassam o que se considera admissível como participação de mercado. ${ }^{33}$ (FRANCESCHINI, 2004, p. 422-424)

A abordagem custo-benefício mostra certa neutralidade, pois nela não há definições e posturas prévias quanto a fusões entre empresas com expressiva participação no mercado. Nesse caso, a avaliação do exercício real ou potencial do poder de mercado pós-fusão é avaliado caso a caso, considerando-se aspectos como a eficiência e outros benefícios que dela resultantes.

$\mathrm{Na}$ abordagem custo-benefício os aspectos estruturais não são totalmente rechaçados. No entanto, os dados que refletem a participação da empresa no mercado e seu grau de concentração somam-se a outras dados relativos aos fatores econômicos pertinentes, tais como as barreiras à entrada e a eventual concorrência estrangeira, os quais podem ser considerados para definir se a pretendida fusão trará, como consequência, a redução significativa ou impedimentos à concorrência por meio de controle discricionário de preços de mercado, controle da produção ou fatores análogos. Essa abordagem concentra-se mais no comportamento real ou potencial das empresas que estão se fundindo do que no domínio de mercado que a fusão pode provocar.

Há também algumas outras dimensões da política de fusões que servem de análise prévia à sua aprovação. Trata-se da extensão em que as fusões devem ser avaliadas quanto à eficiência econômica, o interesse público e aos benefícios que dela advirão, ou a combinação destes elementos. Essa análise revela a interface entre a abordagem política e os critérios aplicados à

33 “O paradigma metodológico atualmente utilizado no Brasil (estrutura-conduta-desempenho) é fortemente influenciado pela escola tradicionalista de Harvard, que revela o pensamento norte-americano ligado a uma conduta de exacerbação do pluralismo igualitário, e que vê na concorrência um valor em si mesmo. Para esta escola, a concorrência vale por si própria, pouco importando o efeito real da concorrência no mercado em relação ao consumidor, posto que o valor a ser protegido é a concorrência em si mesma e não o consumidor ou o mercado. [...] Segundo a escola tradicionalista, toda concentração seria, em princípio, danosa à concorrência." (FRANCESCHINI, 2004, p. 422-424) 
avaliação das fusões, tendo em vista os diversos objetivos da política de concorrência. O que se verifica é que a abordagem estrutural (concentração - participação de mercado) estimularia o poder econômico, mas essa abordagem tende a prejudicar a eficiência econômica.

Há países industrializados nos quais a maior ênfase é dada à eficiência econômica, sendo menos importante o grau de concentração da empresa no mercado. O que é considerado primordial é a conduta a posteriori das empresas fundidas e sua capacidade de exercer poder de mercado, mantendo os preços dos produtos. Sob essa ótima, ainda que se reduza consideravelmente a concorrência, tais fusões podem obter ganhos de eficiência que compensem essa redução e, por isso mesmo, passam a ser explicitamente isentas na legislação de fusões.

Os Estados Unidos aplicam índices de concentração de participação de mercado específicos para avaliar as fusões, mas o processo de revisão dá acentuada ênfase às previsões de exercício pós-fusão de poder de mercado pelas empresas unificadas e suas concorrentes e a melhoria da eficiência daí resultante.

Os diferentes pontos de vista sobre os objetivos da política de concorrência se refletem diretamente nos instrumentos, critérios e padrões legais e econômicos aplicados à gestão da política de concorrência.

O critério da eficiência econômica é tido como unidimensional, ou seja, representa uma avaliação somente nesse sentido, enquanto o interesse público é multidimensional, levando em consideração vários fatores, incluindo, mas não restringindo, a eficiência econômica. Aqui, a autoridade deverá atribuir diferentes pesos a cada um dos fatores na implementação da política de concorrência.

\section{CONSIDERAÇÕES FINAIS}

A concorrência abrange tanto as relações entre empresas quanto suas relações com os consumidores, revelando a existência de uma raiz comum entre o direito do consumidor e o direito da concorrência: a defesa da concorrência visa, em última análise, garantir o ambiente concorrencial como pressuposto axiomático de que esta trará um maior bem-estar ao consumidor pela criação de melhores produtos por preços competitivos (baixos).

Embora possa haver diferentes objetivos da política de concorrência, seus propósitos básicos são mantê-la e estimulá-la, com o intuito de promover a utilização eficiente dos recursos econômicos e proteger a livre iniciativa econômica dos partícipes do mercado. 
Além disso, a política de concorrência é também um meio de alcançar e preservar outras finalidades: pluralismo econômico, descentralização na tomada de decisões econômicas, prevenção dos abusos do poder econômico, promoção das pequenas empresas, justiça e equidade, entre outros valores sociopolíticos. Esses objetivos são variáveis segundo as leis que definem e organizam a ordem econômica, refletindo a natureza adaptável da política de concorrência a objetivos diversos como ciência jurídica que sempre busca equacionar as questões atuais da sociedade e, concomitantemente, mantém inflexível seu conteúdo intrínseco de defender a própria concorrência.

Não é sem razão a preocupação decorrente da inclusão de múltiplos objetivos na política da concorrência, porquanto daí decorre um aumento no risco de conflitos entre esses objetivos e a possibilidade de uma aplicação inconsistente da política de concorrência. É reconhecido que muitas políticas governamentais tendem a promover distorções de mercado, o que impede o processo competitivo e agrega diferentes grupos de pressão que buscam a prevalência de uma intervenção política nas decisões em desprestígio dos valores próprios e científicos do direito da concorrência (eficiência econômica e bem-estar do consumidor).

A política de concorrência deve ser traçada tanto sob a forma pró-ativa quanto reativa ou repressiva, sendo esse último modo aquele que responde as demandas do mercado, tais como questionamentos sobre comportamento abusivo, cartéis, fixação de preços.

No Brasil, o CADE não tem por tradição participar ou colaborar na formulação de políticas públicas de forma pró-ativa. Talvez seja a hora de fomentarmos esse diálogo entre as autoridades antitruste e demais autoridades do Poder Executivo, e mesmo com as agências reguladoras quando investidas de poder de intervir e formular políticas públicas que afetem a política concorrencial para que seus objetivos primordiais sejam preservados.

Tratar-se-ia de uma postura pró-ativa das autoridades concorrenciais para garantir sua promoção no momento em que celebrados acordos institucionais ou políticas públicas que interfiram no funcionamento adequado dos mercados, analisando as condições que prejudicam o desempenho econômico e evitando a adoção de critérios que violem os princípios do livre mercado.

\section{REFERÊNCIAS}

ASSIS GONCALVES NETO, Alfredo de. Direito de Empresa: Comentários aos artigos 966 a 1.195 do Código Civil. $2^{\mathrm{a}}$ ed. São Paulo: RT, 2008. 
BAGNOLI, Vicente. Introdução ao Direito da Concorrência. São Paulo: Singular, 2005.

BRASIL. Lei. 12.529, de 30 de novembro de 2011. Diário Oficial da República Federativa do Brasil. Brasília: Imprensa Nacional, 2011.

BRUNA, Sérgio Varella. O Poder Econômico e a Conceituação do Abuso em seu exercício. São Paulo: RT, 1997.

CALIENDO, Paulo. Direito Tributário e Análise Econômica do Direito. Porto Alegre: Campus Jurídico, 2008.

COMPARATO, Fabio Konder. O Indispensável Direito Econômico. Revista dos Tribunais, São Paulo, n. 353, p. 14-26, março de 1965.

DIMOULIS, DIMITRI. Direito social, regulação e crise do Estado. Fundamentação constitucional dos processos econômicos: reflexão sobre o papel econômico do direito. $2^{\mathrm{a}}$ ed. São Paulo: Revan, 2004.

DUTRA, Pedro. A Livre Concorrência e sua Defesa. Revista de Direito Econômico, Brasília, n. 22, p. 81-94, jan./mar. 1996.

FONSECA, João Bosco Leopoldino da. Lei de Proteção da Concorrência - Comentários à Lei Antitruste. Rio de Janeiro: Forense, 1995.

FONSECA, João Bosco Leopoldino da. Direito Econômico. Rio de Janeiro: Forense, 1998.

FRANCESCHINI, Jose Inácio Gonzaga. Ensaios Reunidos. São Paulo: Singular, 2004.

FORGIONI, Paula A. Os Fundamentos do Antitruste. 2a ed. São Paulo: RT, 1998.

FORGIONI, Paula A. Direito Concorrencial e Restrições Verticais. $2^{\mathrm{a}}$ ed. São Paulo: RT, 2007.

FRANCESCHINI, Jose Inácio Gonzaga. Ensaios Reunidos. São Paulo: Singular, 2004. 
GABAN, Eduardo Molan; DOMINGUES, Juliana Oliveira. Direito Antitruste: O Combate aos Cartéis. São Paulo: Saraiva, 2009.

GOLDBERG, Daniel. Poder de compra e política antitruste. São Paulo: Singular, 2006.

GONÇALVES, Priscila Brólio. Fixação e sugestão de preços de revenda em contratos de distribuição. $2^{\text {a }}$ ed. São Paulo: Singular, 2002.

GRAU, Eros Roberto. Interpretação e Critica da Ordem Econômica. $2^{\mathrm{a}}$ ed. São Paulo: RT, 1991.

HOVENKAMP, Herbert. Antitrust. $4^{\text {th }}$ ed. Saint Paul, Minn.: Thomson West, 2005.

LEOPOLDINO DA FONSECA, Joao Bosco. Direito Econômico. $2^{\mathrm{a}}$ ed. Rio de Janeiro: Forense, 1998.

MONTORO FILHO, Andre Franco. Direito e Economia. "Convite ao Diálogo". 2a ed. São Paulo: Saraiva, 2008.

MOSCOGLIATO, Marcelo. Direito e Economia. Demanda e oferta de decisões judiciais. São Paulo: Saraiva, 2008.

NUSDEO, Ana Maria de Oliveira. Defesa da Concorrência e Globalização Econômica. O contrato da concentração de empresas. São Paulo: Editora Malheiros, 2002.

NUSDEO, Fabio. Curso de Economia. Introdução ao Direito Econômico. $3^{\text {a }}$ ed. São Paulo: RT, 1994.

PINHEIRO, Armando Castelar; SADDI, Jairo. Direito, Economia e Mercados. São Paulo: Elsevier Editora, 2006.

RÊGO, Werson Franco Pereira; RÊGO, Oswaldo Luiz Franco. O Código de Defesa do Consumidor e o Direito Econômico. Revista da EMERJ, Rio de Janeiro, v.5, n. 19, p. 116$131,2002$. 
ROCHA, Silvio Luiz Ferreira da. Responsabilidade Civil do Fornecedor pelo Fato do Produto no Direito Brasileiro. São Paulo: Revista dos Tribunais, 1992.

SOUZA, Wahsington Peluso Albino de. O Regime Jurídico da Concentração de Empresas. Revista de Direito Econômico, Brasília, v. 4, n. 9, p. 16-30, abr. 1978.

SALOMÃo FILHO, Calixto. Direito Concorrencial. As Estruturas. $3^{\text {a }}$ ed. São Paulo: Malheiros Editora, 1998.

SALOMÃO FILHO, Calixto. Regulação da Atividade Econômica. (princípios e fundamentos jurídicos). $2^{\mathrm{a}}$ ed. São Paulo: Malheiros Editora, 2001.

SABADELL, Ana Lucia. Direito Social, Regulação econômica e crise do Estado. São Paulo: Revan, 2006.

SILVA, Américo Luis Martins da. Introdução ao Direito Econômico. $2^{\mathrm{a}}$ ed. São Paulo: Forense, 2001. 